\title{
Erratum
}

\section{Publishing performance in economics: Spanish rankings (1990-1999)}

\author{
Juan J. Dolado ${ }^{1}$, Antonio García-Romero ${ }^{2}$, Gema Zamarro ${ }^{3}$ \\ 1 Department of Economics, Universidad Carlos III de Madrid, c/ Madrid, 126, 28903 Getafe (Madrid), \\ Spain (e-mail: dolado@eco.uc3m.es) \\ 2 Universitat Oberta de Catalunya, 08035 Barcelona, Spain (e-mail: help@eco.vc3m.es) \\ 3 CEMFI, 28014 Madrid, Spain (e-mail: gzamarro@cemfi.es)
}

Spanish Economic Revue 5, 85-100 (2003)

In Sect. 5 (Conclusions) the authors, without noticing, have omitted Universidad Carlos III (UCIII) as one of the top institutions in Spain with larger and better scientific production in Economics over the 1990s. It should therefore be added to the other institutions mentioned in the text. 